\title{
14
}

\section{CLASS DESIGN FOR DEVELOPING PRESENTATION SKILLS FOR GRADUATE RESEARCH STUDENTS}

\author{
Etsuko Tanaka and Emmanuel Manalo
}

\section{Summary}

A one-day workshop was designed to develop graduate research students' presentation skills. It comprised three components for cultivating competencies in constructing (i) a logical story, (ii) helpful slides, and (iii) an engaging conversation. Each component had three steps: instruction of key points, comprehension checking by analyzing an example presentation, and application of learning to own presentation. In addition, at the end of the workshop, students had an opportunity for self-reflection. To assess the usefulness of this workshop, students were asked to make pre- and post-workshop presentations. Evaluation of those presentations revealed that their quality significantly improved in terms of logical flow, usefulness of visuals, and audience engagement. Transfer of skills to a different kind of presentation was also evidenced.

\section{Background}

In the 21st century, graduate students need to develop a much broader set of skills. Doctoral and other graduate research degree holders are now expected not only to be competent in conducting various aspects of research but also to meaningfully contribute to the society they operate in beyond the confines of academia (see, e.g., Hyatt \& Williams, 2011; McNair, 2010; Teijeiro, Rungo, \& Freire, 2013). In the United Kingdom, for example, the Roberts Review (Roberts, 2002) pointed out the necessity of providing appropriate training for doctoral students to cultivate a broad set of general skills, such as interpersonal, communication, and management skills. In response, various training programs for early career researchers have been developed. In the Japanese context, MEXT (the Ministry of Education, Culture, Sports, Science and Technology) has 
increasingly been providing support to universities to promote qualitative and quantitative improvements in the provisions of graduate school education. For example, since 2012 MEXT has been funding a "Program for Leading Graduate Schools," aimed at developing global leadership skills in graduates and competencies in operating inside and outside of academia.

Developing skills for effectively presenting complex ideas to various audiences is essential in both academia and industry in virtually all disciplines (see, e.g., van Ginkel, Gulikers, Biemans, \& Mulder, 2015). Such skills are, for example, considered necessary in many jobs: Bennett (2002) analyzed 1,000 job advertisements targeting new graduates and found that $15 \%$ of the employers mentioned presentation skills as a required skill. Reeves, Denicolo, Metcalfe, and Roberts (2012, p. 4), through a review of the pertinent literature, interviews, and consultation with stakeholders, constructed a framework of skills that researchers need to develop. In this framework, "engagement, influence, and impact" is one of the four domains that characterize excellent researchers, indicating that skills to work with others - ensuring a wider impact of research are vital. In other words, it is crucial for researchers to develop the ability to communicate complex ideas in ways that would make those ideas accessible to different audience groups, including groups of nonexperts.

It is not difficult to find guidebooks and online materials for developing presentation skills, including some that are specifically designed for researchers and graduate students (e.g., Alley, 2007; Schwabish, 2016). Although these resources contain what would generally be considered sensible, practical, and useful advice about presenting research findings and other information to others, they rarely refer to actual research evidence that confirms the effectiveness of the methods they advocate. If anything, they simply refer to other authors who have expressed the same or similar views about what methods or procedures might be effective. One reason is that there are not many studies in the area of developing student competencies in making presentations.

Apart from a scarcity of evidence-based methods, there is also a limited number of studies that have considered what an effective class design might be for developing presentation skills. In their review of previous studies in this topic area, van Ginkel et al. (2015, p. 64) expressed the opinion that only an "incomplete and fragmented picture" of the learning environment for students to learn presentation skills has been revealed.

If effective instruction in presentation skills is to be provided to students, its construction needs to be guided by appropriate design principles, and its contents need to directly address the requirements of developing such skills. One set of research-based design principles comes from the van Ginkel et al. (2015) study mentioned previously. The study synthesized findings from 52 previous studies on the development of oral presentation competence for students at the tertiary level. Van Ginkel and his colleagues were able to derive seven design principles dealing with instruction, learning activities, and assessment strategy. The two principles concerning "instruction" are: clearly communicating objectives that 
are directly related to the criteria of oral presentations, and ensuring that presentation tasks are meaningful to students and relevant to their course of study or subject discipline. The two principles concerning "learning activities" are: providing students with opportunities to observe appropriate models of presentation, and to sufficiently practice their own oral presentations. Both the "instruction" and "learning activities" principles are aimed at enhancing self-efficacy (including reducing anxiety associated with presenting) and oral presentation skills. Finally, the three principles concerning "assessment strategy" are: paying attention to the quality of feedback given to students, involving peers in formative assessment processes, and facilitating self-assessment - all three geared toward the promotion of self-improvement.

In developing a course to cultivate the presentation capabilities of students, it would seem sensible to incorporate the seven design principles indicated by van Ginkel et al. (2015). However, the actual content that would promote the development of specific skills for oral presentation still needs to be determined. It would be important to inculcate understanding about the mechanisms of effective presentations, rather than simply providing students with lots of potentially useful but incongruous tips.

One crucial aspect that needs to be considered in determining the content of the course is the content of the presentation itself: in other words, attention needs to be placed on what the presenter might need to convey to his or her audience. That content needs to be understandable to the audience. In a study by Estrada, Patel, Talente, and Kraemer (2005), reviewers of scientific oral presentations were found to most frequently comment on the content: they considered it important that the key concepts are identifiable and relevance is clearly established. Likewise, criteria statements pertaining to "content" were included in a rubric instrument for assessing oral presentation performance that van Ginkel et al. (2017) designed and validated using an expert group of higher education professionals. These previous findings suggest that the speaker needs to construct a logical "story" that the audience would understand (where "story" pertains to the integrated content and the intended message of the presentation). Brophy and Guerin (2018) questioned the wisdom of the frequent omission of storytelling features in presentations that students make. They referred to previous research demonstrating that storytelling is a powerful tool for clarifying meaning, conveying opinions, and facilitating social interaction - all of which are important functions of presentations. Thus, a course on presentation skills would likely benefit from the inclusion of content that would inculcate the construction of logical story-threads to facilitate these functions.

Two other components that would appear indispensable in determining the content of a course on presentation skills are, firstly, the slides students use and, secondly, their style of presentation. In the previously mentioned study by Estrada et al. (2005), the researchers found that after content, presentation reviewers most frequently commented on these very aspects of presentations. Where "slides" were concerned, their comments focused on clarity, use of graphics, and 
readability, while "presentation style" (also referred to as "presentation delivery aspects" in the research literature, see, e.g., van Ginkel et al., 2015) comments drew attention to various aspects that included clarity, pace, voice, engagement with the audience, answering of questions, and eye contact. Other researchers have likewise noted the importance of slides and other visual aids that presenters use: perhaps the most important point that students need to understand is that the slides are used to help the audience follow the presentation, and hence they need to carefully consider the likely effect of the slides they construct on their intended audience (e.g., Živković, 2014). It should be noted, however, that there are presentation contexts where the use of slides or other visual aids are either not permitted or impractical, so presenters need to be aware of this possible constraint.

Where presentation style is concerned, the key point that students need to understand is that they have to effectively engage with their audience - to grab their attention and maintain it by keeping them involved in their presentation (e.g., Andeweg, de Jong, \& Hoeken, 1998; Chou, 2011; Živković, 2014). A course on presentation skills should therefore include content that would develop students' understanding and competence in the use of slides and their engagement with their prospective audience.

In the study described in this chapter, the principles identified by van Ginkel et al. (2015) were used in addressing the three main competencies - construction of a logical story (content), helpful slides, and an engaging conversation (presentation style) - to develop a workshop on presentation skills aimed at Japanese and international graduate research students for whom English was a foreign language (EFL). The group of students targeted as participants in the study can be considered appropriate because the cultivation of EFL students' abilities to engage with other researchers in the global environment is a high priority not only in Japan but also in other countries. In the United States, for example, the number of international graduate students have been increasing (e.g., Anderson, 2013; Redden, 2013), drawing attention to the need to ensure that those students' skills development requirements are adequately met.

In conducting the workshop, strategies using the "thinking-after-instruction" approach to teaching (Ichikawa, 2004; Ichikawa, Uesaka, \& Manalo, 2017) were employed. In this approach, which is intended to deepen students' understanding of what they learn, teacher instruction of key points is usually followed by activities for checking their understanding. Students are then given tasks that would require them to meaningfully apply what they have learned, and then to engage in self-evaluation and/or reflection about their learning experience. With reference to this approach, three steps within each component were designed: instruction of key points or steps, comprehension checking by analyzing an example presentation, and application and peer feedback. At the end of class, students were also given an opportunity to reflect on what they had learned.

The objective of the corresponding research was to evaluate whether this workshop's design and content effectively delivers some key requirements of 
21st-century education - namely the promotion of communicative competence, deeper learning, and critical thought.

\section{Method}

\section{Participants}

The 16 students who comprised the participants of the present study were enrolled in a Japanese university, taking a graduate-level educational program that included the $\mathrm{PhD}$. One of the aims of the program was to develop various competencies considered necessary for global leadership. All the students provided permission for their workshop data to be used by the first author (who was an instructor in the program) for the purposes of research and program improvement. Additionally, human participants research ethics committee approval was obtained by the first author for the conduct of the research described here.

At the time when the study was conducted, the students were in their first and second years at the Masters level, and their ages ranged from 22 to 36 . Nine students were female and seven were male; five were Japanese and 11 were of various other nationalities (i.e., Chinese, Mongolian, Uzbekistani, and Vietnamese). Although all the students had studied English as a foreign language (EFL), they were sufficiently competent in using English for communication: their IELTS (International English Language Testing System; www.ielts.org) Academic scores ranged from 4.5 to 7.5 . They were from different subject disciplines, which included economics, law, engineering, and physics.

\section{Criteria for determining quality of a presentation}

The first of the design principles that van Ginkel et al. (2015) derived from their research review was clearly communicating to students the presentation course objectives, which should be related to the criteria that will be used for evaluation. Thus, appropriate criteria for deciding the quality indicators of a good presentation were defined (Table 14.1). Note that, although the criteria used in the present study were decided independent of the rubric for oral presentation skills validated by van Ginkel et al. (2017), there are clear congruencies between these two sets of criteria.

In deciding the criteria to use in the present study, it was considered important to place equal emphasis on all three competencies: construction of a logical story, helpful slides, and an engaging conversation. Six criteria statements were defined for each of these competencies, based on the key points covered in the workshop (Figure 14.1a, b, c). For each of these key points, two criteria statements were formulated for determining whether a presenter had achieved that key point. For example, the first key point in the instruction provided for the "logical story" component was "Clarify the key message" (Figure 14.1a). The two criteria statements that corresponded to this key point were: "Key message 
TABLE 14.1 Criteria of a good presentation

Logical story Key message is clearly conveyed.

The reason why the audience should pay attention to the topic of the presentation is communicated clearly.

Sufficient, necessary information is provided to support the key message.

There is no distracting, irrelevant information that makes it hard to understand the key message.

Rather than a mere statement of information, the presentation has a "story."

Appropriate time and slides are allocated to each item of content of the presentation.

Helpful slide Amount of information contained on each slide is appropriate.

Information on slides is congruent and supportive of presenter's speech.

Each item of content is communicated in an appropriate way through the use of text, figure, table, and/or illustration.

Slides do not include too much text.

Design of slides is consistent in terms of color, font, and other visual aspects.

Balance of information and use of white space on the slides help to make the content easily accessible.

\begin{tabular}{|c|c|}
\hline $\begin{array}{l}\text { Engaging } \\
\text { conversation }\end{array}$ & $\begin{array}{l}\text { Presenter uses appropriate techniques (e.g., sharing of feeling, familiar } \\
\text { example, analogy, questioning) to generate audience interest. } \\
\text { Presenter uses appropriate techniques (e.g., sharing of feeling, familiar } \\
\text { example, analogy, questioning) to maintain audience interest. } \\
\text { Presenter makes appropriate and regular eye contact with the audience. } \\
\text { Presenter pauses at appropriate times to check on audience reaction and to } \\
\text { ensure audience has sufficient time to comprehend and reflect on content. } \\
\text { Presenter uses his/her voice effectively to deliver content of the presentation. } \\
\text { Appropriate body language is used. }\end{array}$ \\
\hline
\end{tabular}

(a)

\begin{tabular}{|c|c|c|}
\hline Logical story & & \\
\hline $\begin{array}{l}\text { Instruction } \\
\text { A lecturer shows the following key } \\
\text { steps. } \\
\text { Step1: Clarify key message } \\
\text { - What message do you want to } \\
\text { deliver to the audience? } \\
\text { - What is interesting or valuable for } \\
\text { the audience? } \\
\text { Step2: Select information } \\
\text { - What information does the audience } \\
\text { need to get the message? } \\
\text { Step3: Decide logical flow and } \\
\text { emphasis } \\
\text { - What flow is most understandable } \\
\text { for the audience? } \\
\text { - Which information should you spend } \\
\text { more time on? }\end{array}$ & $\begin{array}{l}\text { Comprehension check } \\
\text { Watching a sample video of } \\
\text { presentation, discuss the } \\
\text { following questions. } \\
\text { - What is the key message? } \\
\text { - How is it different from an } \\
\text { academic presentation } \\
\text { for researchers in his area? } \\
\text { - What can be improved in } \\
\text { his presentation? }\end{array}$ & $\begin{array}{l}\text { Application and feedback } \\
\text { Students make their own } \\
\text { logical story based on what } \\
\text { you learned. } \\
\text { As pair, students explain } \\
\text { their own logical story and } \\
\text { get feedback each other. } \\
\text { Based on feedback students } \\
\text { remake the logical story, } \\
\text { explain toward a different } \\
\text { partner and get feedback } \\
\text { again. }\end{array}$ \\
\hline
\end{tabular}

FIGURE 14.1 a) Flow of class design, part 1, b) Flow of class design, part 2, and c) Flow of class design, part 3. 
(b)

\begin{tabular}{|c|c|c|}
\hline \multicolumn{3}{|l|}{ Helpful slide } \\
\hline $\begin{array}{l}\text { Instruction } \\
\text { A lecturer shows the following key } \\
\text { points. } \\
\text { Point 1: Decide what information } \\
\text { needs to be visualized } \\
\text { - Audience gets information by eyes } \\
\text { and ears at the same time } \\
\text { Point 2: Visualize the information } \\
\text { effectively } \\
\text { - What visual aids are helpful for the } \\
\text { audience? (e.g. Text, Figure, Table, } \\
\text { Picture) } \\
\text { Point } 3: \text { Use design purposefully } \\
\text { - Design must be used for guiding the } \\
\text { audience } \\
\text { - Which information should you spend } \\
\text { more time on? }\end{array}$ & $\begin{array}{l}\text { Comprehension check } \\
\text { Watching a sample video of } \\
\text { presentation again, discuss } \\
\text { the good points and possible } \\
\text { improvement from the } \\
\text { perspective of helpful slide. }\end{array}$ & $\begin{array}{l}\text { Application and feedback } \\
\text { Students make their own } \\
\text { one or two helpful slides of } \\
\text { presentation based on what } \\
\text { you learned using pens and } \\
\text { paper. } \\
\text { As group, students show } \\
\text { slides and explain what to } \\
\text { explain by them. Then they } \\
\text { get feedback group } \\
\text { members. } \\
\text { Group members take turn. }\end{array}$ \\
\hline
\end{tabular}

(c)

\begin{tabular}{|c|c|c|}
\hline \multicolumn{3}{|l|}{ Engaging conversation } \\
\hline $\begin{array}{l}\text { Instruction } \\
\text { A lecturer shows the following key } \\
\text { points. } \\
\text { Point 1: Grab and hold the interest of } \\
\text { your audience } \\
\text { - There are a lot of ways to get your } \\
\text { audience involved (e.g. sharing of } \\
\text { feeling, familiar example, analogy, } \\
\text { questioning) } \\
\text { Point 2: Have interaction with your } \\
\text { audience } \\
\text { - Stay with your audience and watch } \\
\text { their reaction } \\
\text { Point 3: Be a story teller } \\
\text { - Deliver your key message to your } \\
\text { audience using your voice and body } \\
\text { - Practice again and again }\end{array}$ & $\begin{array}{l}\text { Comprehension check } \\
\text { Watching a sample video of } \\
\text { presentation again, discuss } \\
\text { the good points and possible } \\
\text { improvement from the } \\
\text { perspective of helpful slide. }\end{array}$ & $\begin{array}{l}\text { Application and feedback } \\
\text { Students think what to talk } \\
\text { in first one minute of their } \\
\text { presentation and practice by } \\
\text { themselves based on what } \\
\text { you learned. } \\
\text { As group, students talk the } \\
\text { first one-minute of their } \\
\text { presentation and get } \\
\text { feedback group members. } \\
\text { Group members take turn. }\end{array}$ \\
\hline
\end{tabular}

\section{FIGURE 14.1 (Continued)}

is clearly conveyed," and "The reason why the audience should pay attention to the topic of the presentation is communicated clearly" (Table 14.1).

Evaluating/scoring for each criteria statement was undertaken on a 5-point Likert-type scale where the ends were anchored as " $1=$ poor" and " $5=$ good."

This set of criteria was provided to the students at the start of the workshop, both as a guide to course objectives and expectations, and for evaluation of their own and others' presentations. As explained in the next sub-section, the workshop delivery focused on ensuring that students fully comprehended and were able to appropriately use this set of criteria. The same set of criteria was also used 
for instructor/researcher evaluation and scoring of the presentations made by the students (i.e., for teaching and research purposes).

\section{Design and delivery of the workshop}

Before the workshop, the participating students were asked to make two 5-minute presentations in English. One was to explain their own research to a nonspecialist audience (Research Presentation). The other was to introduce the educational program for graduate students that they belonged to (Program Presentation). The presentations were video recorded for the purposes of evaluation (described in more detail in the Results section) - both by the students (to evaluate their own Research Presentation, i.e., self-evaluation with a view to learning and making improvements), and by the researchers (to investigate whether there would be any detectable improvements as a consequence of the workshop provided).

The workshop was delivered one week later by the first author (the instructor). At the beginning of the workshop, the instructor explained that, for the purposes of the workshop, an essential quality of a good presentation would be audience-centeredness: the primary consideration in preparing a "good presentation" should be what the audience would understand, rather than what the presenter would say. Therefore, it would be necessary to prepare or make some adjustments to the presentation based on characteristics of the anticipated audience. For the workshop, the students were asked to assume/imagine that their audience would be people in the general public who were not specialists in the students' research field.

The instructor explained that an audience-centered presentation would pay particular attention to three components: a logical story, helpful slides, and an engaging conversation (Figure 14.2), and that the students would learn about each of these three components in the workshop.

Figures $14.1 \mathrm{a}-\mathrm{c}$ shows the sequence used in providing instruction about these three components. All contents were taught using the three-step process:

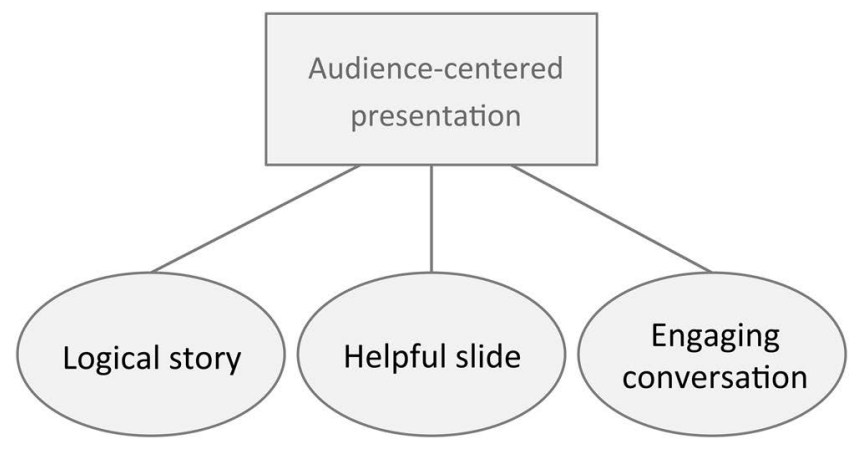

FIGURE 14.2 Three key components of a good presentation. 
instruction of key points and methods, analysis of an example presentation, and application of learned key points to the individual Research Presentations and then providing/receiving peer feedback.

First, the instructor showed the key points on a slide and explained what those points meant. Then she showed a sample video of a presentation and asked the students to analyze it based on the key points they had just learned. The video was 3 minutes long, and the intended audience of the brief presentation it depicted was the general public. It satisfied some but not all of the key points that the students had learned. The students' task was to identify the presentation's shortcomings and to suggest possible ways of improving it. These were discussed in plenary with the instructor. Finally, the students were asked to apply what they had learned to their own presentations. They were then provided opportunities to work with each other in pairs or small groups, to critically evaluate each other's presentations (based on the key points learned) and to provide/receive feedback about what could be improved in those presentations.

At the end of the workshop, the students were given time to review what they had learned during the entire workshop (by going through the instructorprovided notes/materials for each part of the workshop, as well as any other notes they had taken) and to ask any questions they might have had at that point. This final part of the workshop was considered important to provide students with an opportunity to reflect on and check their comprehension of what they were supposed to have learned, and to address any questions or doubts that may occur to them.

After the workshop, students had about one month to improve their Research Presentation and Program Presentation. This length of time (one month) was considered appropriate by the management team overseeing the program that the students were enrolled in, which included the instructor. The students had a lot of other study-related demands on their time, and it was considered important for them to have adequate time to reflect on what they had learned in the workshop, and to be able to implement any modifications to their presentations that they considered appropriate. The revised presentations they made were video recorded like their pre-workshop presentations, and were likewise evaluated using the same evaluation criteria described earlier and shown in Table 14.1.

\section{Assessment of workshop impact}

The students' self-evaluations of their own research presentations, before and after the workshop, were compared by two-way repeated measures ANOVA (3 components $\times 2$ time periods). Also, third party evaluations of their own research and program presentations, before and after the workshop, were compared by two-way repeated measures ANOVA ( 3 components $\times 2$ time periods). In addition, feedback comments from students were examined to gauge their perceptions about various aspects of the workshop. 


\section{Results: Evidence of effectiveness}

\section{Students' self-evaluation}

To check the effect of the workshop, the students' self-evaluations of their own research presentations before and after the workshop were compared. Results revealed that, although the interaction was not significant $[F(2,30)=2.10, p=.14]$, main effects due to components $[F(2,30)=15.54, p<.01]$ and to time $[F(1,15)=16.03, p<.01]$ were significant (Figure 14.3). These results indicate that the students evaluated their own presentation after the workshop higher than before the workshop. In evaluating their presentations in terms of the component parts, they also evaluated their "slides" the highest and their "conversation" the lowest. Multiple comparisons showed that their evaluations of each of these components were significantly different (i.e., slides $>$ story $>$ conversation).

\section{Third-party evaluation}

To check whether there were detectable improvements in the students' presentations apart from their own perceptions, "third-party" evaluations of the presentations before and after the workshop were undertaken by the second author who was not involved in delivery of the workshop and had not met or known any of the student participants. For that evaluation, the video recordings of the student presentations (both research and program presentations) were provided in a mixed up order, making it impossible to determine whether they were recorded before or after the workshop.

If changes in the evaluations of the students' research presentation could be detected, those could at least partly be attributed to the effects of the workshop, which dealt directly with improving such presentations. In contrast, the workshop did not directly deal with more general presentations (such as providing an introduction to a program). Therefore, if improvements in the students' program presentations could be detected, it can be considered as indicative of transfer of knowledge/skills they had acquired through the workshop.

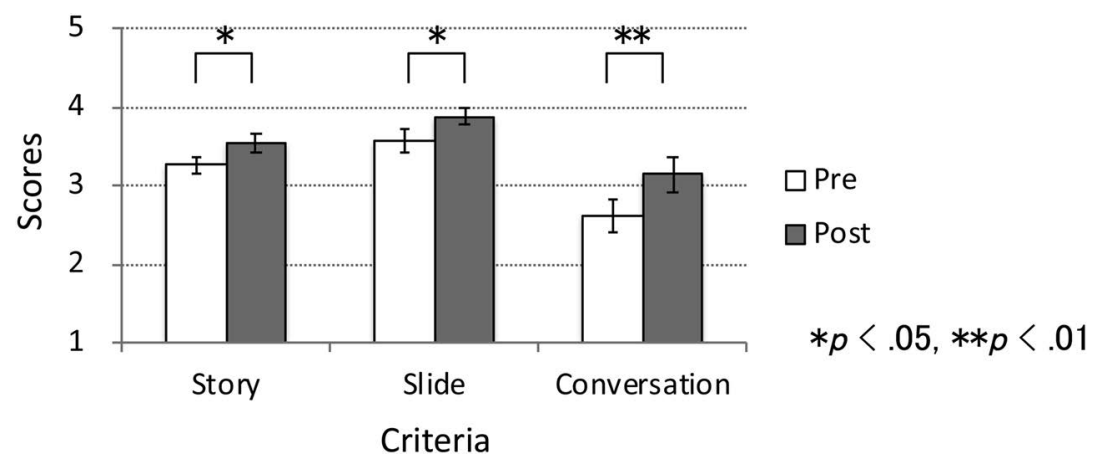

FIGURE 14.3 Self-evaluation scores of students' research presentation. 


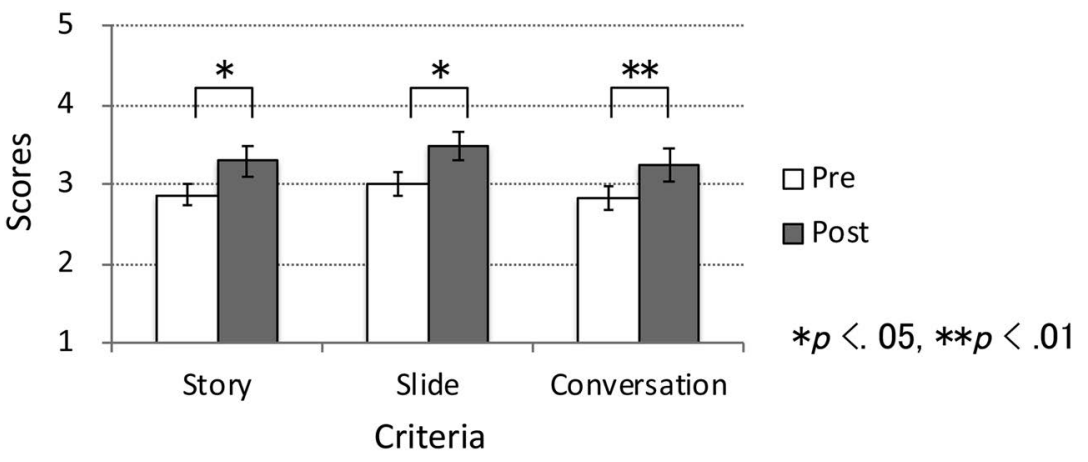

FIGURE 14.4 Third-party evaluation scores of students' research presentation.

In order to check inter-rater reliability, a graduate research student (not one of the students in the research described here) with experience in attending presentation skills workshops evaluated ten of the students' presentations using the same criteria. The correlations of the scores given by the second author and the graduate student for each component were calculated. Pearson's correlation coefficients for story, slide, and conversation components were $r=.64(p=.05), .61(p=.06)$, and $.77(p=.01)$, respectively. These indicate that the two evaluations were not perfectly matched, but they were sufficiently similar (i.e., two components were significantly correlated and one was marginally so). The second author was deemed a more skilled presenter and understood the criteria more deeply, and therefore the decision was made to use his scores in subsequent analyses.

Regarding the research presentations, a two-way repeated measures ANOVA ( 3 components, 2 time periods) showed that interaction effect was not significant $[F(2,30)=.15, p=.87]$, but the main effects due to components $[F(2,30)=$ $3.54, p=.04]$ and time $[F(1,15)=7.25, p=.02]$ were significant (Figure 14.4). The significant effect due to time indicates that the students improved in the quality evaluations of their presentations from the pre-workshop stage to the post-workshop stage. The significant effect due to components, indicates that some components were consistently evaluated more highly than others: multiple comparisons revealed that evaluations of the students' "slides" were significantly higher than their "conversation"; all other comparison results were not significant at the $p<.05$ level.

Regarding the program presentations, the main effect of time $(F(1,15)=11.55$, $p<.01$, and the interaction between components and time were significant $[F(2,30)=3.44, p=.05]$, as shown in Figure 14.5. Simple main effect analysis revealed that improvements of all component were significant at the $p<.05$ level.

\section{Feedback comments from the student participants}

To further examine how the students perceived various aspects of the workshop, they were asked to complete a course evaluation questionnaire at the end of it. 


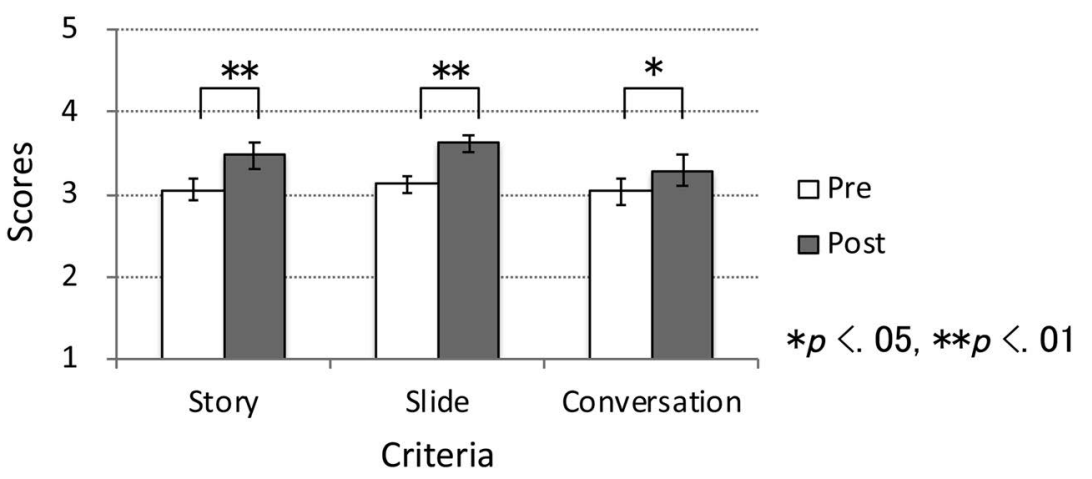

FIGURE 14.5 Third-party evaluation scores of students' program presentation.

The questionnaire included space where students could freely provide comments about their views and perceptions.

The student comments suggested that many of them found the way it was organized, with the three-component structure and three steps, easy to understand. Their comments regarding this aspect included: "I like the structure of the workshop, with three clear main points," and "I think it provides a systematic way to give a presentation and I can check if I make everything properly according to the materials provided in the workshop."

The students also appeared to have found the task of analyzing the video of a presentation helpful toward understanding what the key points meant. Examples of their comments included: "Through watching the example presentation several times, I could analyze it and think from a different perspective," and "I liked analyzing the TED presentation, through which I came to realize some presentation weaknesses similar to my own."

In addition, students' comments suggest they found it helpful to have the opportunity to apply what they had learned to their own presentation, and to provide feedback to each other. For example, students commented: "Although I tried to make my story understandable for other students, they could not understand it," and "Creating an improved slide and showing it to my group member was the most interesting part of today's workshop. By doing this, I could think more from the point of the audience and learned a lot of new ideas."

\section{Discussion}

As noted at the beginning of this chapter, developing competence in presenting complex ideas is considered essential for doctoral and other graduate research students operating in 21st-century environments. Such competence is required not only in academic settings but also in work that the students would likely undertake in their future careers. One concern, however, is that, although there are many methods available for the development of presentation skills, there 
is very little evidence available to indicate the effectiveness of those methods. Furthermore, most of them appear to be based mainly on opinions and intuition, and do not draw upon research-based design principles. In this chapter, effort was made to address these shortcomings by evaluating the effects of a workshop that utilized important components and design principles identified in previous research (e.g., Estrada et al., 2005; Ichikawa, 2004; van Ginkel et al., 2015).

The method described in this chapter appears to have been effective in improving students' research presentations, based on both the students' own presentation evaluations and a "third party" (blinded) evaluation. The students' presentations improved as far as conveying a logical story, presenting helpful slides, and providing an engaging conversation - the components that were addressed in the delivered workshop and evaluated in this research. There is also indication of successful transfer (which is one manifestation of deeper learning on the part of the students) in that, although skills for non-research presentations were not covered in the workshop the students' program presentations also evidenced some significant improvements (on the same components) in the students' second attempt. Furthermore, and perhaps most important in terms of possible application in real educational contexts, the research conducted and reported here had high ecological validity as it was conducted in a real educational setting, with graduate research students for whom the development of presentation skills was of genuine value and necessity. The students also worked on and prepared presentations on topics that were genuinely relevant to them (i.e., the research they were conducting, and the program they were enrolled in).

The workshop included getting the students to analyze and suggest possible ways to improve not only a sample pre-recorded video presentation but also each other's presentations. In this sense, they engaged in critical evaluation. Perhaps more importantly, the students appear to have found this activity of critical evaluation beneficial toward identifying and understanding ways they could improve their own presentations - as indicated by some of the comments they provided in the workshop evaluation questionnaire (examples of which were reported in the previous section). This finding is congruent with the importance that van Ginkel et al. (2015) placed on "self-assessment" as part of the "assessment strategy" component of their design principles. They noted evidence from previous research demonstrating that the incorporation of self-assessment in presentation skills courses has had positive effects on students' oral presentation competence, self-efficacy, confidence, and presentation-related attitudes and perceptions.

In considering why the workshop described in this chapter proved effective in improving students' presentations skills, the most likely reason is that it was designed and delivered using principles, content, and teaching methods that previous research indicates as being appropriate and effective for the task of cultivating such skills in students. As previously noted, the design principles used in the workshop - from van Ginkel et al. (2015) - were drawn from the synthesis of findings from 52 previous studies on the development of oral presentation skills in tertiary students. The content included in the workshop was 
based on what Estrada et al. (2005) found reviewers considered important when evaluating research presentations. And the teaching method utilized was based on Ichikawa's (2004) "thinking-after-instruction" approach, which has previously been demonstrated as effective in promoting not only deeper learning of content but also the use of effective strategies in students (e.g., Ichikawa et al., 2017).

The description of the workshop provided in this chapter ought to be sufficient for other instructors to apply with their students. Furthermore, the method is flexible enough for other content to be added if desired. For example, effective ways of responding to audience questions were not included in the workshop described here due to limited time. Effectively responding to questions was, however, identified in the Estrada et al. (2005) study as being one of the aspects that most reviewers pay attention to.

A number of other improvements could be made to the workshop described in this chapter. One of those is better addressing students' abilities in providing an "engaging conversation," which both the students themselves and the thirdparty evaluator felt was not improved as much as the other two aspects of telling a logical story and constructing/using helpful slides. Perhaps alternative methods of cultivating this ability and/or devoting more time to it could be considered in future provisions of this workshop.

Another possible improvement is that self-reflection could be included at the end of each session (i.e., at the end of the logical story, helpful slide, and engaging conversation component sessions). Previous studies have pointed out the importance of students reflecting on what they have learned and how their understanding changed through the instruction they have received. By describing learning in their own words, students' knowledge and skills could be developed more deeply to make them more likely to become transferable (e.g., Chi, De Leeuw, Chiu, \& LaVancher, 1994; Tajika, Nakatsu, Nozaki, Neumann, \& Maruno, 2007).

From a research perspective, there are also numerous aspects of the workshop that would need to be examined in future investigations. First and foremost, the workshop method used here - and variations of it - ought to be used and evaluated in instructing more groups of students, not only to verify its effectiveness but also to identify aspects that can be improved. Second, the validity and reliability of the presentation criteria used here should be examined more carefully. In this research, the correlations between the second author's and graduate student's score were not very high. Because we do not have one right answer for the question of what a good presentation ought to be like, it is difficult to suggest one set of criteria that would meet everyone's requirements. But we can compare different criteria and consider variations and conditions that could determine appropriateness.

Even though there are some possible improvements that could be made to the workshop for improving graduate students' research presentation skills described in this chapter, the workshop is already effective to some extent - as indicated by the students' own and the third party evaluations reported here. Furthermore, there were indications that through the workshop students were able to transfer knowledge and skills they had learned to the preparation and delivery of another, 
more general kind of presentation (hence, this is indicative of deeper learning, cf. Barnett \& Ceci, 2002). Therefore, for instructors looking for an evidence-based method for developing their graduate students' presentation skills, the workshop design and content described here could be a good starting point. They could then make any adjustments and modifications to it according to the specific requirements of their students and their situations.

\section{References}

Alley, M. (2007). The craft of scientific presentations: Critical steps to succeed and critical errors to avoid. New York: Springer-Verlag.

Anderson, S. (2013, July 15). International students are 70\% of EE grad students in U.S. Forbes. Retrieved September 26, 2018, from https://www.forbes.com/sites/ stuartanderson/2013/07/15/international-students-are-70-of-ee-grad-students-inu-s/\#49b0ce69673e

Andeweg, B. A., de Jong, J. C., \& Hoeken, H. (1998). “May I have your attention?”: Exordial techniques in informative oral presentations. Technical Communication Quarterly, 7, 271-284.

Barnett, S. M., \& Ceci, S. J. (2002). When and where do we apply what we learn? A taxonomy for far transfer. Psychological Bulletin, 128(4), 612-637.

Bennett, R. (2002). Employers' demands for personal transferable skills in graduates: A content analysis of 1,000 job advertisements and an associated empirical study. Journal of Vocational Education and Training, 54(4), 457-476.

Brophy, B., \& Guerin, S. (2018). Stories in conversations and presentations - a comparative study. Innovations in Education and Teaching International, 55, 101-110.

Chi, M. T., De Leeuw, N., Chiu, M. H., \& LaVancher, C. (1994). Eliciting self-explanations improves understanding. Cognitive Science, 18(3), 439-477.

Chou, M. (2011). The influence of learner strategies on oral presentations: A comparison between group and individual performance. English for Specific Purposes, 30, 272-285.

Estrada, C.A., Patel, S. R., Talente, G., \& Kraemer, S. (2005). The 10-minute oral presentation: What should I focus on? American Journal of the Medical Sciences, 329(6), 306-309.

Hyatt, L., \& Williams, P. E. (2011). 21st-century competencies for doctoral leadership faculty. Innovative Higher Education, 36, 53-66.

Ichikawa, S. (2004). Improving learning motivation and skills: Requested strategies for improving academic achievement [in Japanese]. Tokyo, Japan: Shogakukan.

Ichikawa, S., Uesaka,Y. \& Manalo, E. (2017). Three approaches to promoting spontaneous use of learning strategies: Bridging the gap between research and school practice. In E. Manalo, Y. Uesaka, \& C. A. Chinn (Eds.), Promoting spontaneous use of learning and reasoning strategies: Theory, research, and practice for effective transfer (pp. 195-210). London: Routledge.

McNair, D. E. (2010). Preparing community college leaders: The AACC core competencies for effective leadership and doctoral education. Community College Journal of Research and Practice, 34, 199-217.

Redden, E. (2013, July 12). New report shows dependence of U.S. graduate programs on foreign students. Inside Higher Ed. Retrieved September 26, 2018, from https:// www.insidehighered.com/news/2013/07/12/new-report-shows-dependenceus-graduate-programs-foreign-students

Reeves, J., Denicolo, P., Metcalfe, J., \& Roberts, J. (2012). The vitae researcher development framework and researcher development statement: Methodology and validation report. Cambridge, UK: Careers Research \& Advisory Centre (CRAC) Ltd. 
Roberts, G. G. (2002). SET for success: The supply of people with science, technology, engineering and mathematics skills: The report of Sir Gareth Roberts' review. Cambridge, UK: Careers Research \& Advisory Centre (CRAC) Ltd.

Schwabish, J. (2016). Better presentations: A guide for scholars, researchers, and wonks. New York: Columbia University Press.

Tajika, H., Nakatsu, N., Nozaki, H., Neumann, E., \& Maruno, S. (2007). Effects of self-explanation as a metacognitive strategy for solving mathematical word problems Japanese Psychological Research, 49(3), 222-233.

Teijeiro, M., Rungo, P., \& Freire, M. J. (2013). Graduate competencies and employability: The impact of matching firms' needs and personal and personal attainments. Economics of Education Review, 34, 286-295.

Van Ginkel, S., Gulikers, J., Biemans, H., \& Mulder, M. (2015). Towards a set of design principles for developing oral presentation competence: A synthesis of research in higher education. Educational Research Review, 14, 62-80.

Van Ginkel, S., Laurentzen, R., Mulder, M., Mononen, A., Kyttä, J., \& Kortelainen, M. J. (2017).Assessing oral presentation performance: Designing a rubric and testing its validity with an expert group. Journal of Applied Research in Higher Education, 9, 474-486.

Živković, S. (2014). The importance of oral presentations for university students. Mediterranean Journal of Social Sciences, 5(19), 468-475. 